\title{
The Morphology of Electrospun Titanium Dioxide Nanofibers and Its Influencing Factors
}

\author{
Zi Sheng Tang ${ }^{1}$, Nurmin Bolong ${ }^{1, a}$, Ismail Saad ${ }^{1}$ and Janice Lynn Ayog ${ }^{1}$ \\ ${ }^{1}$ Faculty of Engineering, Universiti Malaysia Sabah, 88400 Kota Kinabalu, Sabah, Malaysia
}

\begin{abstract}
Titanium dioxide $\left(\mathrm{TiO}_{2}\right)$ has high photocatalytic activity and it is extensively applied in solar cell technology and environmental science. Electrospinning is acknowledged as the most versatile technique to fabricate nanofibers such as metal oxide nanofibers. Titanium dioxide nanofibers are generally prepared by electrospinning organic solutions containing alkoxide precursors and a carrier polymer with high voltage supply. The paper discusses on electrospun $\mathrm{TiO}_{2}$ nanofibers including the spin dopes preparation history, influencing factors on fiber morphology and fiber characterizations. In particular, the parameters such as spin dopes viscosity, supplied voltage, feeding rate and effect of temperature that affect the morphology of the nanofibers are emphasized. Based on several studies, smaller diameter of $\mathrm{TiO}_{2}$ nanofibers can be produced with lower viscosity solution, higher voltage and lower feeding rate. The heat treatment of $500{ }^{\circ} \mathrm{C}$ reduced the fiber size and produces crystallized anatase $\mathrm{TiO}_{2}$ nanofibers.
\end{abstract}

\section{Introduction}

Titanium dioxide $\left(\mathrm{TiO}_{2}\right)$ have attracted the interests and attentions of the researchers because it is low cost, environmental friendly and exceptional chemical stability with extraordinary optical and electronic properties [1-5]. $\mathrm{TiO}_{2}$ nanofibers with wide band gap are promising material in the applications of photocatalysis, solar cell, optical filter and antimicrobial surface coating [5-7]. $\mathrm{TiO}_{2}$ exists in both amorphous and crystalline forms, in which amorphous form is photocatalytically inactive. There are three crystalline $\mathrm{TiO}_{2}$ phases, namely anatase, rutile and brookie. Of the phases, anatase and rutile are found to be suitable for photocatalytic applications where as brookie is not being tested for photocatalysis [8]. Anatase $\mathrm{TiO}_{2}$ is metastable and exhibits high activities for solar cell applications due to its higher band gap $(3.2 \mathrm{eV})$. On the other hand, rutile $\mathrm{TiO} 2$ is thermodynamically more stable, and due to the low intrinsic photocatalytic activity with lower band gap $(3.0 \mathrm{eV})$, it can be applied in the cosmetic field and tissue engineering [9-12]. One dimensional nanoarchitectures $\mathrm{TiO}_{2}$ offers faster electron transportation rate, high porosity and larger surface [13]. One dimensional nanostructures $\mathrm{TiO}_{2}$ such as whiskers, rods, tubes, wires, belts, spirals and fibers have been produced by sol-gel synthesis, electrochemical fabrication, dip-coating, hydrothermal technique, electroless deposition, crystallize growing method and electrospinning [13-16]. To date, $\mathrm{TiO}_{2}$ nanofibers are prepared by using crystallize growing method and electrospinning. Crystallize growing method takes

\footnotetext{
${ }^{\text {a }}$ Corresponding author : nurmin@ums.edu.my
} 
extremely long growing time and does not produce uniform fibers [13]. Hence, electrospinning has engrossed the attention of the researchers.

Electrospinning appears as a novel, versatile, simple, cost effective and straightforward technique to produce fibers with diameters down to tens of nanometers, from various materials such as polymers, metal oxides and composites $[11,14,16]$. In a typical electrospinning system, there are three basic components to be used: a high voltage supply, a needle of small diameter with syringe that is connected to a syringe pump and a grounded metal collector [17]. The schematic diagram for a typical electrospinning set up can be referred to [18].

\section{Chronology of Spin Dopes Formulation}

The titanium dioxide-based spin dopes can be prepared from organic solutions containing alkoxide precursors and a carrier polymer [19]. The alkoxide precursors are titanium tetraisopropoxide (TTIP) or Titanium (IV) n-butoxide (TNBT), the carrier polymers are polyvinylpyrolidone (PVP) or polyvinyl acetate (PVAc). The solvent for the spin are ethanol, dimethyl formamide (DMF), methanol or isopropanol. Acetic acid is a popular choice of catalyst in the spin dopes preparation among many researchers. A summary of the spin dopes which have been productively electrospun into $\mathrm{TiO}_{2}$ nanofibers by different researchers is presented in Table 1 .

Table 1. Spin dopes to fabricate electrospun TiO2/PVP composite nanofibers.

\begin{tabular}{|c|c|c|c|c|c|c|}
\hline No & Precursor & $\begin{array}{l}\text { Carrier } \\
\text { Polymer }\end{array}$ & Solvent & Catalyst & $\begin{array}{c}\text { Fiber size } \\
(\mathrm{nm})\end{array}$ & Ref. \\
\hline 1 & $\begin{array}{c}\text { Titanium (diisoproproxide) } \\
\text { bis (2,4-pentanedionate) } \\
75 \mathrm{wt} . \% \text { in } 2 \text {-propanol }\end{array}$ & $\begin{array}{c}\text { PVP } \\
(\mathrm{Mw} 1,300,000)\end{array}$ & Ethanol & Acetic acid & $132 \pm 24$ & {$[7]$} \\
\hline \multirow{3}{*}{2} & \multirow{3}{*}{ TNBT } & \multirow{3}{*}{$\begin{array}{c}\text { PVP } \\
(\text { Mw } 1,300,000)\end{array}$} & DMF & \multirow{2}{*}{ Acetic acid } & \multirow{2}{*}{$50-500$} & \multirow{3}{*}{ [9] } \\
\hline & & & $\begin{array}{l}\text { DMF/Isoprop } \\
\text { anol ratio } 1 / 1\end{array}$ & & & \\
\hline & & & Isopropanol & Acetic acid & $200-2000$ & \\
\hline 3 & TTIP & $\begin{array}{c}\text { PVP } \\
(\mathrm{Mw} 1,300,000)\end{array}$ & Ethanol & Acetic acid & $200-800$ & [11] \\
\hline 4 & TTIP & PVP & Ethanol & Acetic acid & $100-200$ & [12] \\
\hline 5 & TTIP & $\begin{array}{c}\text { PVP } \\
(\mathrm{Mw} 1,300,000)\end{array}$ & Ethanol & Acetic acid & $200-2000$ & [16] \\
\hline 6 & TNBT & $\begin{array}{c}\text { PVP } \\
(\mathrm{Mw} 360,000)\end{array}$ & DMF & Acetic acid & $920-1800$ & [19] \\
\hline 7 & TNBT & $\begin{array}{c}\text { PVP } \\
(\mathrm{Mw} 1,300,000)\end{array}$ & Ethanol & Acetic acid & $200-300$ & [20] \\
\hline 8 & TTIP & $\begin{array}{c}\text { PVP } \\
(\mathrm{Mw} 1,300,000)\end{array}$ & Ethanol & Acetic acid & $20-200$ & [21] \\
\hline 9 & TNBT & $\begin{array}{c}\text { PVP } \\
(\mathrm{Mw} 1,300,000)\end{array}$ & Methanol & $\begin{array}{l}\text { Acetyl } \\
\text { acetone }\end{array}$ & $150-200$ & {$[22]$} \\
\hline 10 & TTIP & $\begin{array}{c}\text { PVP } \\
(\mathrm{Mw} 1,300,000)\end{array}$ & Ethanol & Acetic acid & $150-200$ & [23] \\
\hline 11 & TTIP & $\begin{array}{c}\text { PVAc } \\
(\mathrm{Mw} 500,000)\end{array}$ & DMF & Acetic acid & $150-600$ & [24] \\
\hline 12 & TTIP & $\begin{array}{c}\text { PVP } \\
(\mathrm{Mw} 1,300,000)\end{array}$ & Ethanol & Acetic acid & $70-150$ & [25] \\
\hline 13 & TTIP & $\begin{array}{c}\text { PVP } \\
(\mathrm{Mw} 1,300,000)\end{array}$ & Ethanol & Acetic acid & $30-200$ & {$[26]$} \\
\hline 14 & TTIP & $\begin{array}{c}\text { PVP } \\
\text { (Mw 300,000) }\end{array}$ & Ethanol & Acetic acid & $184-343$ & [27] \\
\hline 15 & TTIP & $\begin{array}{c}\text { PVAc } \\
(\mathrm{Mw} 800,000)\end{array}$ & DMF & Acetic acid & $200-600$ & [28] \\
\hline
\end{tabular}


Spin dopes consists of the combination of TTIP, PVP $\left(\mathrm{M}_{\mathrm{w}} 1,300,000\right)$ and acetic acid in ethanol is the most commonly used to fabricate $\mathrm{TiO}_{2}$ fiber.

In this paper, a systematic review is worked out on the electrospun $\mathrm{TiO}_{2}$ nanofibers materials selections and parameters that affect the morphology of the nanofibers and the characterization of $\mathrm{TiO}_{2}$ nanofibers. There are several factors that influence the morphology of the fibers such as applied voltage, flow rate, tip to collector distance and type of collector. However, this paper mainly discusses for the spin dope viscosity, supplied voltage and feeding rate.

\section{Main Factors Influencing the Fibers Morphology}

\subsection{Spin dopes viscosity}

The polymer concentration plays a significant role in determining the diameter of the nanofibers. The increase in polymer concentration may consequently elevates the viscosity of the spin dopes significantly [29]. Furthermore, the rise in alkoxide precursor (TTIP) may cause a slight increase in the spin dopes viscosity. In $\mathrm{TiO}_{2}$ nanofiber fabrication, the increase of polymer concentration cause the expansion of fabricated fiber diameter [21]. Lee et al. [30] found that when the PVP concentration is increased from $0.04 \mathrm{~g} / \mathrm{ml}$ to $0.10 \mathrm{ml}$, the fibers size increase significantly from $125 \mathrm{~nm}$ to $275 \mathrm{~nm}$ while the TTIP concentration raises from $0.12 \mathrm{~g} / \mathrm{ml}$ to $0.18 \mathrm{~g} / \mathrm{ml}$ results in increase of the fiber diameter from $200 \mathrm{~nm}$ to $280 \mathrm{~nm}$. This has been proved later by [11] and [16]. Thus, the viscosity is greatly affected by the polymer concentration in the spin dopes. When the spin dopes viscosity is higher, under a fixed supplied voltage and feeding rate condition, the fiber formation initiation cannot take place due to the insufficient force to stretch the fibers to the thinner size [11]. At a higher concentration of TTIP, a higher supplied voltage is needed in order to initiate the fiber formation. In order to produce smaller diameter of $\mathrm{TiO}_{2}$ fibers, it is suggested that the spin dopes should have a lower concentration of PVP in order to obtain smaller size of $\mathrm{TiO}_{2} / \mathrm{PVP}$ composite fibers.

\subsection{Supplied voltage}

Bharwaj and Kundu [18] stated that the fibers can be formed provided the supplied voltage is at the threshold stage which subsequently induces the essential charges on the solution to initiate the electrospinning process. In the fabrication of $\mathrm{TiO}_{2}$ nanofibers, the fibers' diameter can be reduced by raising the supplied voltage. $\mathrm{Li}$ and $\mathrm{Xia}$ [21] proved that the fibers size is abruptly decreased from 110 $\mathrm{nm}$ to $55 \mathrm{~nm}$ as the supplied voltage is raised from $5 \mathrm{kV}$ to $20 \mathrm{kV}$. In addition, the mean diameter of the fabricated fibers decreases from $110 \mathrm{~nm}$ to $80 \mathrm{~nm}$ when the supplied voltage of $15 \mathrm{kV}$ is increased to $25 \mathrm{kV}$ [31]. Higher supplied voltage leads to a greater stretching on the spin dopes as the higher electrostatic repulsive force is formed and effectively reduce the fibers size. This causes rapid evaporation of the solvent, which contribute in the fiber size reduction [18]. However, discontinuity in nanofibers occurs when the supplied voltage exceeded $20 \mathrm{kV}$, causing the occurrence of over pulling effect with the fiber breakage [13,31-32]. Thus, to fabricate a continuous smaller fibers, the supplied voltage should be within $15-20 \mathrm{kV}$. The optimized $\mathrm{TiO}_{2}$ nanofibers can be generated with the supplied voltage of $18.4460 \mathrm{kV}$ based on the morphology analysis [16].

\subsection{Feeding rate}

Feeding rate, which is tunable by the syringe pump, influences the jet velocity and the transfer rate. Faster feeding rate of spin dopes may result in wider size of fabricated $\mathrm{TiO}_{2}$ fibers [21, 30]. The study by Jung et al. [13] showed that composite $\mathrm{TiO}_{2} / \mathrm{PVP}$ fibers' mean diameter increased from $120 \mathrm{~nm}$ to $180 \mathrm{~nm}$ with the increment of flow rate from $0.1 \mathrm{~mL} / \mathrm{hr}$ to $0.3 \mathrm{~mL} / \mathrm{hr}$. When the jet velocity is high, the volume ejected is greater and thus it caused the solution is electrospraying sequel of insufficient stretching under the constant supplied voltage [33]. High transfer rate of the jet solution cause the jet 
to reach the collector rapidly without proper drying time and reflex in larger fibers formation [18]. Thus, the feeding rate should provide adequate time for the solvent to evaporate before reaching collector. Moreover, it is suggested that the optimized morphology of $\mathrm{TiO}_{2}$ composite nanofibers can be obtained at $0.70 \mathrm{~mL} / \mathrm{hr}[16]$.

\subsection{Heat treatment}

Heat treatment is needed after the spin dopes is electrospun on the collector. The electrospun $\mathrm{TiO} 2 / \mathrm{PVP}$ composite nanofibers are heated up to $500^{\circ} \mathrm{C}$ to eliminate PVP and remaining solvent which can reduce the size of fibers [13]. Although calcined at a temperature of $200{ }^{\circ} \mathrm{C}$ is enough to eliminate the polymer and solvent, the fibers may stay in amorphous form. Thus, it is suggested that the $\mathrm{TiO}_{2} / \mathrm{PVP}$ composite nanofibers is to be sintered up to $500^{\circ} \mathrm{C}$ to obtain pure $\mathrm{TiO}_{2}$ nanofibers in crystallize form. However, for sintering more than $600^{\circ} \mathrm{C}$, the fibers will transform from anatase to rutile phase $[11,13,34]$. A shrinkage of $35-70 \%$ of the diameter when the fibers is annealed at the temperature of $450-500{ }^{\circ} \mathrm{C}[13-14,36]$.

In general, X-ray Diffraction (XRD) is used to determine whether the nanofibers are in amorphous or crystallize form. However, for crystallized $\mathrm{TiO}_{2}$ nanofibers, $\mathrm{XRD}$ is used to identify whether the fibers are either in anatase or rutile phase. Figure 1 shows the heat treatment of $\mathrm{TiO}_{2}$ nanofibers at different temperature, form and different phase of $\mathrm{TiO}_{2}$. The nanofibers were converted from amorphous to crystallize form after annealing at $550^{\circ} \mathrm{C}$; beyond $400^{\circ} \mathrm{C}, \mathrm{TiO}_{2}$ exhibits in anatase phase then at rutile phase when is calcined at $700^{\circ} \mathrm{C}$.

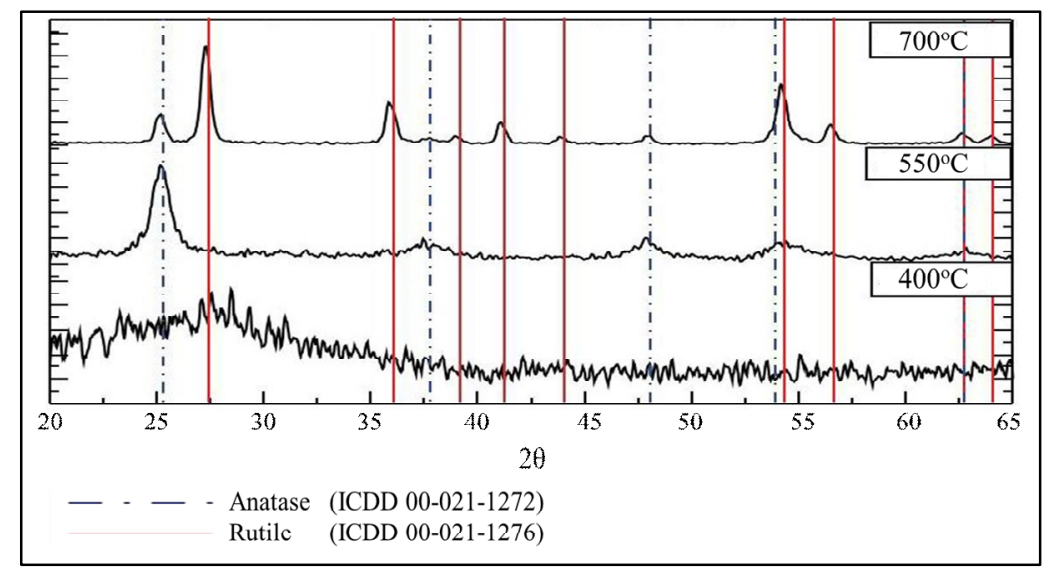

Figure 1. $\mathrm{XRD}$ analysis for $\mathrm{TiO}_{2}$ nanofibers at different temperature of heat treament. $\mathrm{TiO}_{2}$ is in amorphous form at heat treatment below $400{ }^{\circ} \mathrm{C}$; showing crystallize form at higher temperature with $500^{\circ} \mathrm{C}$ showing anatase phase and $700{ }^{\circ} \mathrm{C}$ showing rutile phase [11].

\section{Fibers Characterizations}

\subsection{Morphology analysis}

The morphology of the fabricated composite nanofibers can be revealed by using scanning electron microscope (SEM). The micrograph of SEM provides the diameter of the fibers and the surface condition of the fibers. The diameter of the generated nanofibers as presented in Table 1 was determined and observed by using SEM. The electrospun TiO2/PVP composite nanofiber is straight with smooth surface without heat treatment. The $\mathrm{TiO} 2$ fiber is found to have rough surface due to crystallization of $\mathrm{TiO}_{2}$ when it is calcined. When the fiber is sintered to $700^{\circ} \mathrm{C}$ and above, the surface structure shows some burl and to have nanocrytallize structure. This is because when the calcination 
temperature increases, the crystallize growth of the $\mathrm{TiO}_{2}$ fibers is better [5]. This is further done by $[11,13,34-35]$. The surface structure of the fibers is clearly shown with lower accelerating voltage (e.g. $5-10 \mathrm{kV}$ ) of SEM can provide the clearer surface structure image. Meanwhile, in order to measure the diameter of the fiber, the magnification should be range $10 \mathrm{k}$ to $200 \mathrm{k}[11,16,35]$.

\section{Conclusions}

$\mathrm{TiO}_{2}$ nanofibers can be produced by using electrospinning process. The diameter of the nanofibers is tunable by changing the parameters especially the applied voltage, feeding rate and PVP concentration. An optimized fiber was suggested to produce at $18 \mathrm{kV}, 0.7 \mathrm{~mL} / \mathrm{hr}$ with $6.5 \%$ PVP concentration. Based on the desired applications, the $\mathrm{TiO} 2$ nanofibers may transformed from amorphous to crystallize form at $450-500^{\circ} \mathrm{C}$. It can be converted from anatase to rutile by calcination of $700{ }^{\circ} \mathrm{C}$ and above.

\section{Acknowledgment}

The authors would like to acknowledge to Universiti Malaysia Sabah for the financial support under the research grant (SBK0205-TK-2015) and Minister of Education (RACE 0006-TK-2012).

\section{References}

[1] H.J. Chen, L. Wang and W.Y. Chiu, Chelation and solvent effect on the preparation of titania colloids, Materials Chemistry and Physics, 101, 12-19, (2007).

[2] D.S. Xu, J.M. Li, Y.X. Yu and J.J. Li, From titanates to $\mathrm{TiO}_{2}$ nanostructures: Controllable synthesis, growth mechanism, and applications, Science China Chemistry, 55(11), 2334-2345, (2011).

[3] H. Gao, J. Tian, H. Zhu, F. Tan and W. Zhang, Effects of Fe doping on the optical and magnetic properties of $\mathrm{TiO}_{2}$ films deposited on Si substrates by sol-gel route, J. of Sol-Gel Science and Technology, 74, 521-527, (2015).

[4] A.K. Prasad, F. Nose, N.C. Raut, S. Tripura Sundari, M. Kamruddin, S. Dash and A.K. Tyagi, Phase selective gas sensing properties of nanostructured $\mathrm{TiO}_{2}$ thin films, Proc. of Int. Conf. on Nanoscience, Engineering and Technology, IEEE, 532-535, (2011).

[5] B. Ding, C.K. Kim, H.Y. Kim, M.K Seo and S.J Park, Titanium nanofibers prepared by using electrospinning method, Fibers and Polymers, 5(2), 105-109, (2004).

[6] S. Mishra and S.P. Ahrenkiel, Synthesis and characterization of electrospun nanocomposite $\mathrm{TiO}_{2}$ nanofibers with Ag nanoparticles for photocatalysis applications, J. of Nanomaterials, 2012(16), $1-6,(2012)$.

[7] W. Nuansing, S. Ninmuang, W. Jarenboon, S. Maensiri and S. Seraphin, Structural characterization and morphology of electrospun $\mathrm{TiO}_{2}$ nanofibers, Material Science and Engineering B, 131, 147-155, (2006).

[8] S. Watson, D. Beydoun, J. Scott and R. Amal, Preparation of nanosized crystalline $\mathrm{TiO}_{2}$ particles at low temperature for photocatalysis, Journal of Nanoparticle Research, 6, 193-207, (2004).

[9] R. Chandrasekar, L. Zhang, J.Y. Howe, N.E. Hedin, Y. Zhang and H. Fong, Fabrication and characterization of electrospin titania nanofibers, J. of Materials Science, 44, 1198-1205 (2009).

[10]B.H.Q. Dang, M. Rahman, D. MacElroy and D.P. Dowling, Conversion of amorphous $\mathrm{TiO}_{2}$ coating into their crystalline form using a novel microwave plasma treatment, Surface and Coatings Technology, 2015, 235-240, (2011).

[11]B. Caratao, E. Carneiro, P. Sa, B. Almeida and S. Carvalho, Properties of electrospun $\mathrm{TiO}_{2}$ nanofibers, Journal of Nanotechnology, 2014, 1-5, (2014).

[12]M. Mali, S. An, M. Liou, S.S. Al-Deyab and S.S. Yoon, Photoelectrochemial solar water splitting using electrospun TiO2 nanofibers, Applied Surface Science, 328, 109-114, (2015). 
[13] W.H. Jung, N.S. Kwak, T.S. Hwang and K.B. Yi, Preparation of highly porous $\mathrm{TiO}_{2}$ nanofibers for dye-sensitized solar cells (DSSCs) by electro-spinning, Applied Surface Science, 261, 343352, (2012).

[14]T. Mathews, R.P. Antony, P.K. Ajikumar, S. Chakraborty, S. Dash, A.K. Tyagi, Fabrication of $\mathrm{TiO} 2$ nanofibers by electrospinning technique, Proc. of Int. Conf. on Nanoscience, Engineering and Technology, IEEE, 540-542, (2011)

[15]M. Boehme and W. Ensinger, Mixed phase anatase/rutile titanium dioxide nanotubes for enhanced photocatalytic degradation of methylene-blue, Nano-Micro Letters, 3(4), 236-241, (2011).

[16]N. Sarlak, M.A.F. Nejad, S. Shakhesi and K. Shabani, Effects of electrospinning on titanium dioxide nanofibers diameter and morphology: An investigation by Box-Wilson central composite design (CCD), Chemical Engineering J., 210, 410-416, (2010).

[17]Z.M. Huang, Y.Z. Zhang, M. Kotaki and S. Ramakrishna, A review on polymer nanofibers by electrospinning and their applications in nanocomposites, Composites Science and Technology, 63, 2223-2253, (2003).

[18]N. Bhardwaj and S.C. Kundu, Electrospinning: A fascinating fiber fabrication technique, Biotechnology Advances, 28, 325-347, (2010).

[19]N.M. Tikekar, J.J. Lannutti, Effects of humidity on titania-based polyvinylpyrolidone (PVP) electrospun fibers, Ceramics International 38, 4057-4064, (2012).

[20]C. Wang, X. Zhang, C. Shao, Y. Zhang, J. Ying, P. Sun, X. Liu, H. Liu, T. Xie and D. Wang, Rutile $\mathrm{TiO}_{2}$ nanowires on anatase $\mathrm{TiO}_{2}$ : A branched heterostructured photocatalysts via interfaceassisted fabrication approach, J. of Colloid and Interface Science, 363, 157-164, (2011).

[21] D. Li and Y. Xia, Fabrication of titania nanofibers by electrospinning, Nano Letters, 4(3), 555$560,(2003)$.

[22]D. Sabba, S, Agarwala, S.S. Pramana and S. Mhaisalkar, A maskless synthesis of $\mathrm{TiO}_{2}$-nanofiberbased hierarchical structures for solid-state dye-sensitized solar cells with improved performance, Nanoscale Research Letters, 9(14), 1-9, (2014).

[23]R. Nirmala, H.K. Kim, R. Navamathavan, C. Yi, J.J. Won, K. Jeon, A. Yousef, R. Afeesh and M. El-Newehy, Photocatalytic activities of electrospun tin oxide doped titanium dioxide nanofibers, Ceramics Int., 38, 4533-4540, (2012).

[24]N.A.M Barakat, A.M. Hamza, S.S. Al-Deyab, A. Qurashi and H.Y. Kim, Titanium-based polymeric electrospun nanofiber mats as a novel organic semiconductor, Materials Science and Engineering B, 177, 34-42, (2012).

[25]J.Y. Park and I.H. Lee, Characterization and morphology of prepared titanium dioxide nanofibers by electrospinning, J. of Nanoscience and Nanotechnology, 10, 3402-3405, (2010).

[26]H. Jamil, S.S. Batool, Z. Imran, M. Usman, M.A. Rafiq, M. Willander and M.M. Hassan, Electrospun titanium diaoxide nanofibers humidity sensors with high sensitivity, Ceramics Int., 38, 2437-2441, (2012).

[27]X. Wang, R.A. Gittens, R. Song, R. Tannenbaum, R. Oliver-navarrete, Z. Schwartz, H. Chen and B.D. Boyan, Effects of structural properties of electrospun $\mathrm{TiO}_{2}$ nano-fiber meshes on their osteogenic potential, Acta Biomater, 8(2), 878-885, (2012).

[28] M.Y. Song, D.K. Kim, K.J. Ihn, S.M. Jo and D.Y. Kim, Electrospun $\mathrm{TiO}_{2}$ electrodes for dyesensitized solar cells, Nanotechnology, 15, 1861-1865, (2004).

[29] P. Heikkilä and A. Harlin, Parameter study of electrospinning of polyamide-6, European Polymer J., 44, 3067-3079, (2008).

[30]D.Y Lee, B.Y. Kim, S.J. Lee, M.H. Lee, Y.S. Song and J.Y. lee, Titania nanofibers prepared by electrospinning, J. of the Korean Physical Society, 48 (6), 1686-1690, (2006).

[31]Z.S. Tang, N. Bolong, I. Saad and F.M. Said, Effects of supplied voltage and flow rate on morphology of electrospun titanium oxide nanofibers, Proceedings of Hong Kong International Conference of Engieering and Applied Sciences, Hong Kong, (2013).

[32]C. Tekmen, A, Suslu and U. Cocen, Titania nanofibers prepared by electrospinning, Materials Letters, 62, 4470-4472, (2008). 
[33] S. Zargham, S. Bazgir, A. Tavakoli, A.S. Rashidi and R. Damerchely, The effect of flow rate on morphology and deposition area of electrospun nylon 6 nanofibers, J. of Engineered Fibers and Fabrics, 7(4), 42-49, (2012).

[34]H. Park and W.M. Sigmund, Thermally controlled crystallization of electrospun $\mathrm{TiO}_{2}$ nanofibers, Advances in Science and Technology, 71, 80-85, (2010).

[35]J.Y. Park and I.H. Lee, Characterizations and morphology of prepared titanium oxide nanofibers by electrospinning, J. of Nanoscience and Nanotechnology, 10, 3402-3405, (2010).

[36]L. Francis, A.S. Nair, R. Jose, S. Ramakrishna, V. Thavasi and E. Marsano, Fabrication and characterization of dye-sensitized solar cells from rutile nanofibers and nanorods, Energy, 36, 627-632, (2011). 